\title{
El diseño de lo siniestro en la serie televisiva Dark
}

\author{
Antonio Alaminos Fernández|antonio.alaminos@ua.es \\ Universidad de Alicante
}

\author{
Palabras clave \\ "Serie televisiva", "Dark", "siniestro", "psicoaná- \\ lisis", "Freud”, "semiótica” \\ Sumario \\ 1.Introducción \\ 2.Objetivos y Metodología \\ 3. Análisis \\ 3.1 El sonido \\ 3.2 La presencia diegética del psicoanálisis \\ 3.3 La imaginaría psicoanalítica de lo siniestro \\ 3.3.1 Los dobles y la identidad \\ 3.3.2 La repetición como compulsión del deseo \\ 3.4 La relatividad de lo absoluto \\ 3.5 Personajes siniestros \\ 4. Conclusiones \\ 5. Bibliografía
}

\section{Resumen}

En su tercera temporada la serie televisiva Dark fue la más popular del mundo en la plataforma Netflix, convirtiéndose en una serie de culto que avala su empleo como estudio de caso. En esta serie destaca lo siniestro como rasgo fundamental, logrando dicho efecto gracias al entrelazamiento de dos enfoques. El enfoque psicoanalítico es la base del argumento y de gran parte de la presentación audiovisual, siendo citado explícitamente en paratextos y diálogos. Este enfoque encuentra un límite en la ruptura con el tiempo lineal, que desordena las genealogías y con ello los patrones básicos de las relaciones de parentesco que fundamentan en el psicoaná-

lisis varios complejos. No obstante, el desorden temporal ofrece la oportunidad de plasmar nuevas formas de lo siniestro al diluir la barra significante, con personajes que se engendran a sí mismos o permutando posiciones generacionales. Surge la posibilidad de mostrar significados sin significantes (fenómenos sin nombre) así como significantes que pierden su significado. La ruptura sintagmática de la narración difumina el sentido de las acciones y la identidad de los personajes, dando con ello una mayor significación a las manifestaciones psicoanalíticas de lo siniestro.

\section{Cómo citar este texto:}

Antonio Alaminos Fernández (2021): El diseño de lo siniestro en la serie televisiva Dark en Miguel Hernández Communication Journal, Vol. 12 (1), pp. 119 a 140. Universidad Miguel Hernández, UMH (Elche-Alicante). DOI: https://doi.org/10.21134/mhcj.v12i.934 


\section{The design of the uncanny in the TV serial Dark}

Antonio Alaminos Fernández| antonio.alaminos@ua.es

Universidad de Alicante

Keywords

"Television serials". "Dark; unncany", "psychoanalysis", "Freud", "semiotics"

Summary

1. Introduction

2.Objectives and Methodology

3. Analysis

3.1 The sound

3.2 The diegetic presence of psychoanalysis

3.3 The psychoanalytic imagery of the sinister

3.3.1 Doubles and identity

3.3.2 Repetition as a compulsion of desire

3.4 The relativity of the absolute

3.5 Sinister characters

4. Conclusions

5. Bibliography

\section{Abstract}

In its third season, the television series Dark was the most popular in the world on the Netflix platform, becoming a cult series that supports its use as a case study. In this series the uncanny stands out as a fundamental feature, achieving this effect thanks to the intertwining of two approaches. The psychoanalytic approach is the basis of the argument and of a large part of the audio-visual presentation, appearing explicitly in paratexts and dialogues. This approach finds a limit in the break with linear time, which messes up genealogies and, with it, the basic patterns

of kinship relationships that underpin various complexes in psychoanalysis. However, temporal disorder offers the opportunity to shape new forms of the uncanny by diluting the signifying bar, with characters that create themselves or by swapping generational positions. In this way, the suppression of the temporal order offers the possibility of showing meanings without signifiers (nameless phenomena) as well as signifiers that lose their meaning. The syntagmatic rupture of the narrative blurs the meaning of the actions and the identity of the characters, thereby giving greater significance to the psychoanalytic manifestations of the uncanny.

\section{How to cite this text:}

Antonio Alaminos Fernández (2021): El diseño de lo siniestro en la serie televisiva Dark en Miguel Hernández Communication Journal, Vol. 12 (1), pp. 119 a 140. Universidad Miguel Hernández, UMH (Elche-Alicante). DOI: https://doi.org/10.21134/mhcj.v12i.934 


\section{Introducción}

Lo siniestro ha sido y es un concepto de gran interés para la escuela psicoanalítica al estar vinculado con la noción de angustia, que para Freud es la causa de la represión. En esencia la sensación de siniestro se genera como una expresión de la angustia. Dado que el psicoanálisis consideró las manifestaciones artísticas como un material analítico apropiado para documentar sus teorías, la literatura de su época les facilitó un extenso repertorio. González Requena (1998) recuerda que:

En un primer momento, lo siniestro, en tanto fenómeno estético, irrumpe en el siglo XIX de la mano del Romanticismo y la literatura gótica (E. Th. A. Hoffmann, Shelley, Stoker) configurando todo un género literario -la literatura fantástica- que aún hoy prolonga su influencia (González Requena, 1998: 22).

Lo siniestro, como también sucedió con el humor, se convirtió en una vía de acceso al estudio de la angustia utilizando como material analítico la creación artística. La comunicación entre el psicoanálisis y el arte fue desde su inicio bidireccional; si el psicoanálisis recurre a ejemplos artísticos para ilustrar sus propuestas analíticas, finalmente él también se convierte en un recurso para la creación artística (como ejemplifica el surrealismo y el automatismo creativo). Las cuestiones básicas aquí son dos. Qué define lo siniestro en el psicoanálisis y cómo se logra recrearlo artísticamente.

Freud publica en 1919 un ensayo sobre lo siniestro donde propone que su fundamento psicológico no está en lo desconocido o nuevo (como postula Jentsch) y sí en lo oculto que ha sido revelado (Schelling). Trías (2006) describe como en lo siniestro "se repite, pues, algo familiar e íntimo, pero olvidado por medio de la censura, superado y refutado por la conciencia del sujeto" (Trías, 2006: 39-40).

$[\ldots]$ lo siniestro, no sería realmente nada nuevo, sino más bien algo que siempre fue familiar a la vida y que sólo se tornó extraño mediante el proceso de su represión. $\mathrm{Y}$, encerrado todo en una esfera, lo siniestro se presenta como lo fantástico que se produce en lo real, “o cuando lo real asume enteramente el carácter de lo fantástico (Trías, 2006: 35).

Por ello, según González Requena (1997) “algo, en el interior del sujeto, en su inconsciente, habría quedado encerrado, reprimido, y al retornar a su conciencia sería vivido como siniestro" (González Requena, 1998: 53).

Freud (1919), a partir de su análisis de dos relatos de Hoffman, propone varios procedimientos para crear la impresión de siniestro: "lo siniestro en las vivencias se da cuando complejos infantiles reprimidos son reanimados por una impresión exterior, o cuando convicciones primitivas superadas parecen hallar una nueva confirmación" (Freud, 1919: 12). La clave para crear algo siniestro se encuentra en expresar complejos (como el de castración) o recurrir a ideas pertenecientes a fases iniciales del desarrollo psicológico (animismo, omnipotencia del pensamiento).

En lo siniestro se identifica la reaparición de conceptos como la muerte, el odio, el deseo, 
la omnipotencia del pensamiento, las amenazas al yo... aquello que al llegar a la adultez se supone superado mediante la represión, pero que regresa, invocado por mecanismos de defensa como la proyección. En dicho marco analítico la realización de un deseo reprimido puede llegar a ser siniestro. Según Trías:

Se da la sensación de lo siniestro cuando algo sentido y presentido, temido y secretamente deseado por el sujeto, se hace, de forma súbita, realidad. (.../...) Siniestro es un deseo entretenido en la fantasía inconsciente que comparece en lo real; es la verificación de una fantasía formulada como deseo, si bien temida (Trías, 2006: 35).

La escuela freudiana interpreta lo siniestro desde la pérdida (lo reprimido), mientras que otras propuestas psicoanalíticas pondrían el énfasis en la presencia; así Lacan explica lo siniestro como la irrupción inesperada de algo donde no existía la sensación de faltar de nada. En su aplicación práctica a la creación artística las dos aproximaciones conducen al mismo diseño expresivo, diferenciándose desde un punto de vista clínico en donde ubican la fuente de la angustia. Lo esencial de la propuesta psicoanalítica es que lo reprimido da forma y formulación a la producción de lo siniestro. En otras palabras, que siempre es factible conectar un evento siniestro con una represión que se ha manifestado (complejo o fase animista). En términos prácticos, las formas para producir lo siniestro adquiere la variabilidad de lo reprimido y sus procesos.

La teoría psicoanalítica no es, evidentemente, la única explicación sobre qué es y cómo se crea artísticamente la sensación de lo siniestro. Desde la semiología, Eco e Irazazábal (2007) proponen una definición que se centra en la ruptura de la relación entre significado y significante: "es el principio por el que se rigen los episodios de fantasmas y otros acontecimientos sobrenaturales, en los que nos espanta o nos causa horror algo que no es como debiera ser" (Eco e Irazazábal, 2007: 311). Lo sinestro desde un enfoque semiótico se caracteriza en que algo no es como debería. Un deber ser que refiere especialmente a la necesaria existencia de una relación significante.

En dicha línea argumental González Requena (1998), reflexionando sobre lo siniestro en la literatura, diferencia entre el concepto de "terror", que atribuye a la tensión narrativa propia del romanticismo basada en el suspense, del "horror", del que afirma es su forma más pura de expresión en la corriente naturalista. Profundizando en dicha idea, González Requena (1997) señala como "en el discurso naturalista, en cambio, el horror mismo aparece ligado al hecho, a su facticidad, a la vez que independiente, en el límite, de toda trama narrativa y, por ello mismo, inquietantemente, vacío de significado" (Gonzáles Requena, 1998: 24). Comparten época, por lo tanto, el "horror vacui" que utilizara Praz para describir la decoración en la época Victoriana (horror al vacío físico o ausencia de significantes) y el horror al vacío de significado de la literatura fantástica.

Desde el enfoque semiótico se propone una definición de lo siniestro como un avistamiento de la brecha existente entre los significantes y sus significados, tanto culturalmente cerrados (visibles) como abiertos (vacíos no codificados). Esta definición remite a la propuesta por González Requena (1997): 
Si esa incertidumbre de la que Freud nos hablaba afecta al sometimiento del mundo al orden del significante - la realidad-, podemos definir lo siniestro como la descomposición, en ausencia de soporte simbólico, de la barra significante. Quiebra de la barra significante que, en los textos de la posmodernidad, se manifiesta como descomposición de los ejes semánticos nucleares - antropológicos -sobre los que se estructura toda civilización: vida/muerte, hombre/animal, hombre/mujer. Lo que entonces aparece, en ausencia de la barra significante, en su lugar, no es otra cosa que lo monstruoso, lo informe, es decir, lo real en tanto que siniestro (González Requena, 1997: 72).

En el modelo semiótico, un niño con voz de anciano (o viceversa) es siniestro como resultado de la antonimia temporal entre el significado de la edad (imagen) y el significado del tono de voz infantil (sonido). En ese sentido, estudiando otro concepto próximo a lo siniestro (lo abyecto), donde la repulsión se sobrepone como rasgo sobre el horror, Kristeva (1989) identifica su desencadenante en la borrosidad de la barra significante (a diferencia de su desaparición y colapso que señala González Requena para lo siniestro). Así,

No es la falta de limpieza o de salud lo que causa la abyección sino aquello que perturba una identidad, el sistema, el orden, lo que no respeta los bordes, las posiciones, las reglas. Lo que está en medio, lo ambiguo, lo mezclado (Kristeva, 1989: 27).

La sensación de abyecto o de siniestro serían la consecuencia emocional del juego plástico entre significados y significantes. En ese núcleo semiótico que destaca González Requena (conceptualmente complementario pero independiente de la interpretación psicoanalítica) se alojaría una fuente alternativa de expresión de lo siniestro. Y no solo como un potencial. Conde (2006), reflexionando sobre la naturaleza artificial del lenguaje y las discontinuidades que revelan las traducciones, sugiere que el lenguaje no es solo artificio para construir lo siniestro, sino que las palabras son en sí mismas una cuna potencialmente siniestra.

En ese sentido, la serie Dark (2017-2020) se caracteriza por una trama argumental de carácter metafísico, en la que la angustia y lo siniestro ocupan un papel central. Esta serie fue estrenada en diciembre de 2017 y consta de tres temporadas. Creada para la plataforma Netflix por Baran bo Odar (director y guionista) y producida por Jantje Fiese, es la primera serie alemana y se caracteriza por la profusión de citas filosóficas y literarias que reflexionan sobre la naturaleza del ser, la identidad o la angustia vital. Una angustia latente que manifiesta en su título. Entre las diferentes acepciones de "dark" en inglés se incluyen como adjetivo: tenebroso, lúgubre, lóbrego, misterioso, entenebrecido, escondido, hosco; como sustantivo puede referir a la oscuridad o las tinieblas.

Como se mostrará más adelante, lo siniestro es el registro clave de su argumento y su ambientación. Así, al igual que lo hace el tiempo, hay un continuo retorno a los mismos escenarios, espacios cerrados, angustiosos y claustrofóbicos. La elección de los escenarios, como el bosque de Grünewald en los alrededores de Berlín considerado entre los más tenebrosos del mundo o el cementerio elegido para rodar las escenas de la iglesia, Südwestkirchhof Stahnsdorf, donde está enterrado el director de Nosferatu, Friedrich 
Wilhelm Murnau evidencian la intención de reforzar la lógica narrativa de lo siniestro. Los productos audiovisuales poseen múltiples recursos, como por ejemplo el argumento, la narración/discurso, la voz/sonido o las imágenes, que permiten que en la ficción exista un repertorio ampliado de efectos siniestros. Freud destacaba como "la ficción dispone de muchos medios para provocar efectos siniestros que no existen en la vida real" (Freud, 1919: 12). Más aún en la actualidad, donde las tecnologías han maximizado las posibilidades de expresión artísticas.

\section{Objetivos y metodología}

La generación de emociones en las audiencias es un objetivo complejo por lo que resulta especialmente interesante conocer cómo se ha diseñado. El carácter artificial de una obra artística sea una serie de televisión o una pieza musical, permite interrogarse sobre el proceso seguido. Tanto en lo referido a qué principios inspiran el diseño que produce una emoción como a los procedimientos y recursos narrativos empleados. Una pregunta de interés, entre otras razones, en la medida que ofrece la oportunidad de conocer mejor las motivaciones, las creencias o los sistemas de valores de los individuos que reaccionan a dichos estímulos artísticos.

Los objetivos de esta investigación son indagar en qué forma las propuestas del psicoanálisis ofrecen un marco teórico para conocer los procedimientos utilizados en la creación de la sensación de siniestro en la serie Dark. En ese sentido, no se trata de aplicar el psicoanálisis como una clave de lectura e interpretación de la obra artística. El objetivo es revelar y describir cómo se han utilizado los recursos que propone el psicoanálisis para producir lo siniestro.

La diferencia entre los relatos de Hoffman y los creadores de la serie es, entre otras, que estos últimos conocen los análisis freudianos de lo siniestro, tal y como corrobora las citas psicoanalíticas. Precisamente, las citas y fragmentos seleccionados para el análisis responden al criterio de ofrecer de una forma directa y explicita evidencias sobre la intencionalidad de los creadores de la serie. Así, un capítulo que se inicia con un intertítulo que cita a Freud muestra en tanto que paratexto (Genette, 1989a) un significado especial. Más aún cuando en el trascurso de la acción la reflexión es incorporada como parte del diálogo.

En este análisis, la serie es considerada como un discurso fragmentado en temporadas y capítulos, donde la comprensión de su lógica interna exige recuperar la estructura de relaciones latentes (paradigmática y sintagmáticamente) que tejen la trama (Alaminos, 1999; Casetti, 2005; Penalva, et al., 2015). Su fragmentación viene condicionada por su naturaleza de serie televisiva. Carrasco Campos (2010: 183) pone de relieve que lo particular de la teleserie como categoría audiovisual es su carácter de "narración seriada de diferentes relatos de ficción, fragmentados en diferentes capítulos". La forma expresiva que adopta el continente (teleserie) no contradice la existencia de unidad discursiva que le aporta un sentido global a pesar de que su emisión genere discontinuidad temporal y fragmentación de la trama argumental, 
Para ello, y partiendo de la propuesta de los ejes paradigmáticos y sintagmáticos de Saussure (1973), se aplica el análisis estructuralista y semiótico conforme a las propuestas metodológicas de Lévi-Strauss (1968) y Barthes (2003). El estudio de la serie se realiza desde la metodología estructuralista que Lévi-Strauss (1968) sintetizaba como "de una sistemática, cuya finalidad es identificar tipos, analizar sus partes constitutivas, establecer entre ellos correlaciones" (Lévi-Strauss, 1968: 29). Dicho marco analítico resulta fundamental para comprender el diseño de una serie en la que las historias suceden en dos mundos paralelos y entrelazados.

Los paradigmas definen agrupaciones de núcleos de significado articulados en conjuntos opuestos. Estas estructuras pueden superponerse de forma que revelen un sistema común en diversas variantes sobre el mismo tema. En la serie, los dos mundos paralelos son expresiones superpuestas de un mismo paradigma y por ello reductibles a un solo mundo de ficción. Sera precisamente su potencialidad para analizar incluso los significantes que deben su existencia a oposiciones sintagmáticas o encadenadas (secuenciales) lo que le hace especialmente valioso en este caso. El colapso de las relaciones sintagmáticas desplaza el sentido hacia las relaciones paradigmáticas convirtiéndolas en esenciales para apreciar el diseño psicoanalítico de la serie.

\section{Análisis}

Vamos a presentar una sinopsis de la serie en tanto que unidad discursiva. La trama argumental desnuda e integrada puede parecer simple. Sin embargo, en una narración es significativo no solo qué sucede, sino también cómo sucede. Por ello, es importante tener presente que para el espectador la acción se desarrolla envuelta en el misterio y sin un sentido aparente. La trama es, en su despliegue capítulo tras capítulo, tanto paradigmáticamente como sintagmáticamente oscura y solamente al finalizar ofrece respuesta a los interrogantes que han surgido durante las tres temporadas.

En sinopsis, un relojero para evitar que mueran su hijo, nuera y nieto construye una máquina del tiempo que destruye su mundo, creando otros dos (el origen) mundos paralelos donde el tiempo adopta la forma de ciclo repetitivo (nudo). En uno de los mundos existe un personaje (Jonas) que no existe en el alternativo. Eso identifica los mundos como el mundo de Adam (Jonas) y el mundo de Eva (Martha). Los dos quieren terminar con el nudo (eterno retorno), pero disienten en donde está el hecho (origen) que los creó. Los dos están equivocados y es una científica, Claudia, quien descubre que son dos mundos "artificiales" creados por el uso de una máquina del tiempo en un mundo original. Los dos personajes centrales (Jonas-Adam y Martha-Eva) viajan al pasado del mundo original, evitan la invención de la máquina del tiempo y restauran el tiempo en el mundo original, haciendo desaparecer los dos mundos artificiales atrapados en el nudo temporal. 


\subsection{El sonido}

En la serie Dark la función del sonido desborda ampliamente la labor de ambientación. Así, si bien el sonido diegético anuncia las transiciones entre tiempos y mundos (un ruido amenazante y siniestro), la música extradiegética formada por las canciones incluidas en su banda sonora ha sido seleccionadas tanto por el contenido de sus letras como sus propiedades musicales (cuerdas, voz operística, sonido industrial y oscuro, etc.).

En las letras de las canciones se identifican los temas y la expresión emocional de lo que sucede. Las letras de las canciones funcionan, actuando desde la metatextualidad de Genette (1989a), como un discurso paralelo y coordinado que sobrevuela el argumento y subraya la circularidad, el tiempo, la libertad, el destino, con muchas de ellas mostrando claros referentes psicoanalíticos. Un ejemplo de referencia musical al psicoanálisis es la frase: en mi mente esta la llave; esta forma parte del estribillo en la canción interpretada por Peter Gabriel My body is a cage.

Respecto a las propiedades musicales de la ambientación sonora, la serie emplea un repertorio musical caracterizado por un sonido angustioso, sinestro y atemorizante (Alaminos-Fernández, 2014, 2019). La banda sonora minimalista e instrumental (creada por Ben Frost) está compuesta para causar desazón en el espectador y su tema central, Goodbye (Apparat, proyecto del músico electrónico alemán Sascha Ring) reproduce sonidos mecánicos y voces desesperanzadas. El resto de las músicas utilizadas en la serie son, sobre todo, una selección de pop experimental europeo, con musicalidad sombría y siniestra que ilustra los estados psicológicos de los personajes (Alaminos-Fernández, 2020).

Una ambientación musical sombría que se encuentra en armonía con la ambientación visual, con predominio de escenas nocturnas o con interiores en penumbras, bosques umbríos, cuevas o iluminaciones mediante velas. La coordinación entre el tratamiento visual y el musical es exhaustiva, definiendo un ambiente opresivo y cerrado del que algunos personajes, de forma reiterada, afirman desear escapar.

\subsection{La presencia diegética del psicoanálisis}

En términos narrativos, el psicoanálisis aparece en diferentes niveles ofreciendo claves heurísticas sobre el sentido oculto en la trama. Desde su expresión diegética como parte de la acción, a su aparición como paratexto e incluso mediante un narrador omnisciente extradiegético que se ubica entre los mundos de la ficción y el espectador. De modo totalmente explícito en una cita de Freud (2000), que se menciona dos veces en la serie y en los intertítulos. A efectos de notación de las referencias a los contenidos de la serie, se indicará la temporada mediante la letra $\mathrm{T}$ y el episodio dentro de dicha temporada con la letra E. La primera mención es en un escrito (anónimo, T2: E6) enviado a la policía para que averigüe que sucede (inspector Clausen), y la segunda la pronuncia el único personaje sin nombre de la serie. Un personaje que se supone en el origen de todo, que atraviesa todos los tiempos y los mundos, llevando a ellos el orden preestablecido, portando una identidad que se mantiene firme y con el mismo propósito en todas sus edades. La cita es reproducida aquí en el contexto del texto original de Freud y revela la intención última de 
los creadores de la serie.

Hay en la vida mucho simbolismo de esta clase, que solemos no advertir. Cuando me propuse la tarea de traer a la luz lo que los hombres esconden, y no mediante la compulsión de la hipnosis, sino a partir de lo que ellos dicen y muestran, lo creí más difícil de lo que realmente es. El que tenga ojos para ver y oídos para oír se convencerá de que los mortales no pueden guardar ningún secreto. Aquel cuyos labios callan, se delata con las puntas de los dedos; el secreto quiere salírsele por todos los poros. Y por eso es muy posible dar cima a la tarea de hacer consciente lo anímico más oculto (Freud, 2000: 68).

Los creadores de la serie refieren a una episteme psicoanalítica como clave interpretativa de parte de sus registros narrativos. En otras palabras, bastaría con un esfuerzo hermenéutico sobre lo que se manifiesta y se dice para comprender que se esconde tras la represión. La idea de que todo significa algo aparece en la vOz de múltiples personajes, sugiriendo que saben algo fundamental que es ignorado por la audiencia. Así, el personaje Noah afirma que "Nunca nada sucede en vano, ni el más mínimo aliento ni el paso más pequeño ni la palabra más simple ni el dolor... un milagro eterno único" (Noah, T1: E10). En definitiva, todo lo que sucede tiene una explicación para quien sabe leerla.

Sin embargo, en la narración la paradoja surge cuando los dos personajes que actúan como analistas (Adam y Eva), supuestamente fuera de los ciclos del tiempo, y por lo tanto actuando como observadores externos (por eso pierden el nombre que empleaban sujetos a la temporalidad) buscan la solución al "nudo" dentro de los dos mundos. Habitando lo imaginario, las diferentes explicaciones (científicas, religiosas, filosóficas) que van explorando nunca pueden escapar de la fantasía. Esa búsqueda del principio de realidad dentro de lo imaginario es incapaz de encontrar la solución, al estar sujeta a la lógica interna de la ficción. La pregunta sobre cuál de estos dos mundos es el real y cual el imaginario no tiene respuesta, dado que los dos son imaginarios. En palabras de Freud en su ensayo sobre lo siniestro:

El poeta provoca en nosotros al principio una especie de incertidumbre, al no dejarnos adivinar [...] si se propone conducirnos al mundo real o a un mundo fantástico, producto de su arbitrio. Lo siniestro se da, frecuente y fácilmente, cuando se desvanecen los límites entre fantasía y realidad; cuando lo que habíamos tenido por fantástico aparece ante nosotros como real (Freud, 2000: 2491).

$\mathrm{Y}$ viceversa, lo que se tenía por real resulta ser una fantasía. Finalmente, la ciencia (el personaje Claudia) descubre la solución mediante la experimentación: recupera el principio de realidad. La solución al "nudo temporal" en que viven los dos mundos se encuentra en la realidad real: un mundo originario en el que el cumplimiento del principio del placer (recuperar de la muerte los afectos perdidos) destruye la realidad y da lugar a dos mundos imaginarios patológicos. Solo reconocer la realidad real (mundo originario) y el motivo de la falla (consecuencias aberrantes del cumplimiento del deseo) permite disolver y superar la vida irreal (ficción) en la que habitan los personajes, tal y como se muestra en el diagrama 1. 
Diagrama 1. Esquema psicoanalítico del argumento de la serie Dark

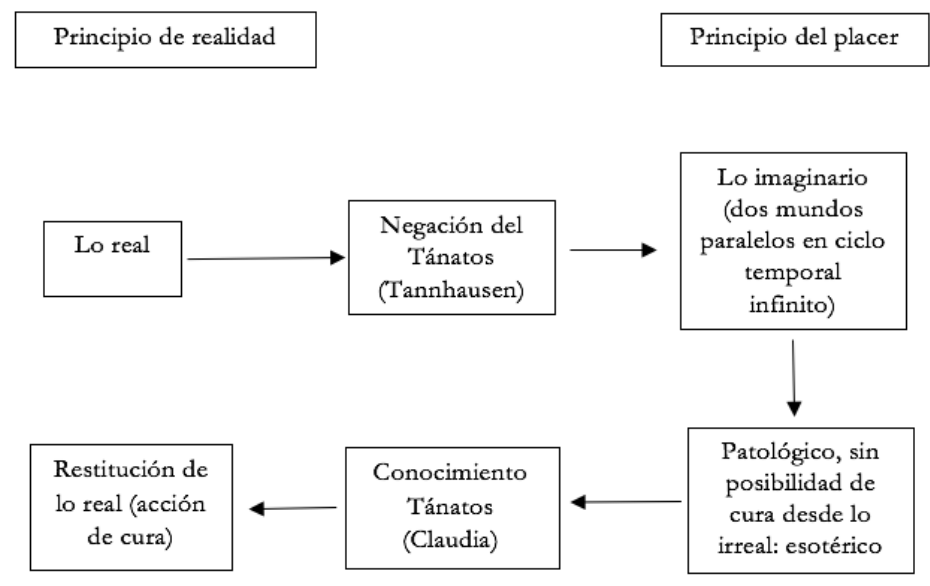

Fuente: elaboración propia

En conjunto, el argumento se fundamenta en el conflicto entre los principios de placer y de realidad. Tras la pauta "macro" de eterno retorno (Nietzsche, 2005) se esconde la angustia individual de la repetición de los actos como consecuencia del deseo. Si no podemos elegir lo que deseamos, somos esclavos de un impulso desconocido:

El hombre es una criatura peculiar. El deseo motiva todas sus acciones y el dolor forja su carácter. Por más que intente reprimir el dolor, reprimir el deseo... no puede liberarse de la eterna esclavitud de sus sentimientos. Mientras la tormenta azote dentro de él, no podrá encontrar la paz, ni en la vida ni en la muerte. Por eso día a día, hará lo que debe hacer. El dolor es su navío y el deseo, su brújula. El hombre es capaz de esto (Adam, T2: E7).

El desenlace mismo forma parte de la clínica psicoanalítica. No es solo que metodológicamente la explicación última de lo imaginario se encuentra en la realidad, por lo que la búsqueda de soluciones dentro del discurso patológico (los dos mundos creados) es inútil. Es que al descubrirse la existencia de una realidad real que debe ser restituida, todos los personajes asumen que deben ser curados y sus mundos desaparecer al ser una angustiosa anomalía.

\subsection{La imaginería psicoanalítica de lo siniestro}

La angustia que produce el contacto entre dos mundos paralelos que viven en un ciclo infinito de eterno retorno es la clave de arco narrativa en la generación de lo siniestro. Este se plasma en la serie Dark utilizando múltiples elementos propios de la figuración psicoanalítica, muchos de los cuales se encuentran en los cuentos de Hoffman analizados por Freud. Así, aparecen mutilaciones o situaciones que para el psicoanálisis son muy significativas: niños muertos con los ojos quemados (castración), una joven muda que es 
a su vez paradójicamente su propia madre (ravage), un policía tuerto, un niño con la cara desfigurada... Una pérdida de los ojos, que para Freud puede ser la sustitución del órgano sexual, y en este caso, con un sacerdote como personaje de referencia en lugar del padre.

Superpuesta a la organización de contenidos psicoanalítica se entreteje una parafernalia científica para argumentar la posible realidad de los dos mundos y el viaje en el tiempo (Schrödinger, Einstein, agujeros de gusano...), así como continuas citas a referencias filosóficas (teoría del eterno retorno de Nietzsche, Kant, Heidegger) explorando el sentido de una vida atrapada en el tiempo, religiosas (medalla de san Cristóbal, iglesias, cuadro de Adam y Eva) o esotéricas (triqueta, símbolo del infinito...). Todas ellas son, en esencia, un recurso retórico para aportar verosimilitud, intentando explicar tanto racional como irracionalmente la posible realidad de los mundos imaginarios, que finalmente son reducidos a la nada.

Por su peso argumental destaca uno de los recursos para producir lo sinestro identificado por Freud en "Los elixires del diablo": el retorno constante de lo semejante. Un retorno que adquiere dos formas de expresión: el retorno del semejante, vinculado al tema del doble y el retorno de lo semejante mediante la repetición involuntaria.

\subsubsection{Los dobles y la identidad}

En la serie Dark la definición de los personajes se apoya sobre el triángulo formado por el tiempo, el ser y su sentido en el mundo, utilizando propuestas filosóficas de Kant, Nietzsche o Heidegger. Para Heidegger (2012) el ser humano es lo ontológicamente más lejano de sí mismo, y el descubrimiento del sentido que revela la posibilidad de una existencia auténtica produce la angustia de la inhospitalidad (Unheimlichkeit) del "ser-en-el mundo en cuanto tal". Con ello, el tiempo funda la inhospitalidad del ser-en el-mundo dando un carácter trágico a la existencia humana, puesto que el tiempo es también inconsistente en sí mismo.

La inconsistencia del tiempo, tal y como fundamenta la trama en Dark, es el desencadenante de las existencias inhóspitas e inconsistentes con ellas mismas. Uno de los personajes clave afirma "Es admirable que las personas no se quiebren ante la futilidad de su propia existencia. Un ciclo interminable de vida y muerte. ¿Dónde está el origen del sufrimiento?” (Adam, T2: E1).

El doble, en la interpretación de lo siniestro, aparece ya en los cuentos de Hoffman que analizó Freud. Los dobles, el encuentro de un personaje consigo mismo en otro mundo o tiempo, ponen en cuestión la noción de identidad (ser algo único) que se mantiene igual a sí misma. La imagen del doble es frecuentemente vinculada con el pensamiento primitivo. Así, Morin (2001):

El doble es efectivamente universal en la humanidad antigua. Tal vez sea el único gran mito universal. Mito experimental; su presencia, su existencia no ofrecen duda: se le ve en el reflejo, en la sombra, en los sueños; se le siente y adivina en el viento y en la naturaleza. Todos vivimos acompañados de nuestro doble. No tanto copia conforme, y más aún que un alter ego: un ego alter, un yo otro (Morin, 2001: 32). 
En el doble, según Freud, el carácter siniestro solo puede obedecer a que es una formación perteneciente a épocas primitivas ya superadas en la formación de la psique. Una época en la que tenía un sentido menos hostil que cuando reaparece en periodos posteriores. Para Freud, como para Rank (2004), la noción del doble aparece en fases tempranas, "primero como un elemento que asegura la supervivencia (el alma inmortal que sobrevive a la muerte)" (Quirós Fernández, 2017: 129), pasando posteriormente a ser un mensajero que anuncia la muerte. En ese sentido, tanto el doble como la noción de fantasma generan problemas evidentes para definir y operar sobre la realidad.

La propuesta de Lacan enfatiza precisamente el efecto siniestro de la presencia. Para Lacan "Lo Unheimlich es lo que surge en el lugar donde debería estar la menos phi". Puesto que "no hay imagen de la falta", "cuando algo surge ahí, lo que ocurre (...) es que la falta viene a faltar" (Lacan, 2006: 52). La falta de la falta (donde se espera la ausencia o vacío y en su lugar hay algo) es la versión opuesta a Freud donde es la falta la que rige lo siniestro. Para Lacan lo siniestro que se aprecia en la imagen del doble es una señal de angustia, pues aparece en el lugar previsto para la falta, donde no tiene que aparecer nada irrumpe súbitamente algo.

En la serie la identidad viene cuestionada desde dos ángulos: los viajes en el tiempo y la existencia de un mundo paralelo. Ambos escenarios dan lugar al encuentro con el otro yo, con el doble. En la primera temporada de Dark prima sobre todo la noción de doble en el tiempo: un personaje joven se encuentra con su versión adulta o infantil. Sin embargo, conforme la serie va avanzando y se revela la existencia de dos mundos paralelos, las opciones de encuentros anacrónicos dentro de uno de ellos o entre los dos se multiplican; en la práctica el número máximo de encuentros de personajes con ellos mismos en mundos o edades diferentes es de $15(6 *(6-1) / 2=15$. Para un personaje, existe la posibilidad de encontrarse con 15 dobles de sí mismo, como consecuencia de las asincronías en sus líneas temporales en dos mundos. Esta posibilidad es llevada casi al límite en la tercera temporada, donde se entrecruzan hasta 14 líneas temporales individuales.

El diagrama 2 muestra gráficamente las posibilidades de encuentro de un personaje con su doble. Existen dos mundos notados por la letra M, siendo M1 el correspondiente al mundo 1 y M2 el del mundo 2. El subíndice thace referencia al tiempo en el que la narración ubica al personaje dentro de cada mundo. Dado que la serie establece 33 años como el intervalo de referencia, $t$ expresa el presente de la narración en curso, t-33 al pasado hace 33 años y $\mathrm{t}+33$ al futuro. 
Diagrama 2. El sistema espaciotemporal de dobles en Dark

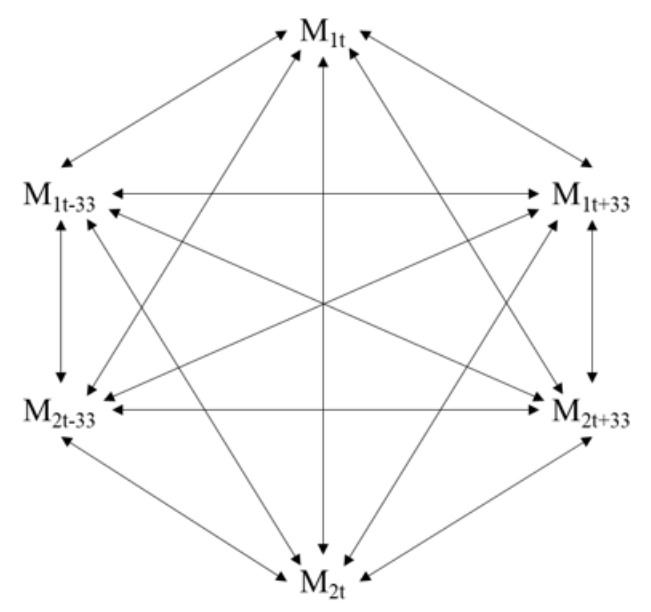

Fuente: elaboración propia

Estos encuentros de los personajes consigo mismos muestran como la imagen del doble es conocida (familiar) pero es también desconocida. Algo que en la lectura psicoanalítica se encuentra en la definición misma de siniestro. Ese reconocimiento del desconocido, en el caso de edades diferentes, evidencia sin lugar a duda que son el mismo y no lo son. En palabras de Noah, "Mi yo adulto quería decirme algo, pero no podía, porque si supieras lo que yo sé ahora no harías lo que debes hacer para que yo llegue a este preciso momento. No podría existir tal y como soy ahora, si tu no sigues el mismo camino que seguí yo". Algo semejante sucede cuando el personaje se encuentra con su misma edad en otro mundo. Físicamente el doble aparenta la misma identidad, pero es muy diferente en sus intenciones y las circunstancias que le rodean. En el caso del doble, lo conocido desconocido (por efecto del tiempo o de sus experiencias) genera la sensación de siniestro.

En ese sentido, la serie muestra una fórmula de siniestro novedosa: el doble temporal que es invariante, que no cambia. El personaje "el extraño" siempre aparece en grupo mostrando las tres edades, como niño, adulto y anciano; sin embargo, los tres actúan con una única intención y propósito. Impasibles, no hay fisuras ni dudas o conversación entre ellos. Lo sinestro se manifiesta como una identidad que, más allá de la edad, es única y permanente. La idea de una persona que no cambia con el tiempo y siempre mantiene el mismo propósito en todos sus dobles temporales es una variante que explora de forma original lo siniestro desde la invarianza del cambio.

\subsubsection{La repetición como compulsión del deseo}

En la serie Dark la concreción del eterno retorno, los ciclos que se repiten, son denominados el nudo. Es una fuente de sorpresas, especialmente en la primera temporada, donde el tiempo es el principal parámetro de anomalías. 


\section{MHCJ Vol. 12 (1) | Año 2021 - Artículo n 6 (173) - Páginas 119 a 140 - mhjournal.org}

Confiamos en que el tiempo se mueve en forma lineal. Que avanza siempre y de modo constante hacia el infinito. Pero la distinción entre pasado, presente y futuro no es más que una ilusión. El ayer, el hoy y el mañana no son consecutivos. Están conectados en un círculo sin principio ni final. Todo está conectado (Tannhaus, T1: E1).

La angustia que surge del encadenamiento existencial que propone el eterno retorno, sea conocido o solo intuido, se encuentra presente en las vivencias de los personajes. Los personajes que conocen la anomalía temporal (Adam-Martha) viven lo siniestro como repetición del mismo ciclo. Para ellos, el mito del eterno retorno es real y han vivido miles de veces las mismas vidas. Son conscientes del nudo vital y lo intentan romper en los dos mundos. Como caracteres, muestran el agotamiento de vivir fuera del tiempo, y se les representa siempre muy envejecidos, ejerciendo un papel siniestro al mantener oculto un plan o propósito.

Junto a ellos, conviven personajes que no son conscientes de la situación. En su vida cotidiana lo siniestro surge de su encadenamiento a rutinas y actos provocados por el deseo. El eterno retorno en la vida cotidiana procede de la falta de libertad real. Un deseo expresado en la afirmación de Schopenhauer: podemos hacer lo que queremos, pero no podemos elegir lo que queremos. Eso pone el control fuera del individuo, en unas manos desconocidas: lo inconsciente y reprimido. Uno de los personajes, Jonas adulto, afirma que no somos libres en lo que hacemos porque no somos libres en lo que queremos, frase que se repetirá posteriormente como un eco por otros personajes, usando diferentes expresiones "Lo que siente el corazón no tiene explicación, siente lo que quiere” (Doris Tiedemman, T3: E4). Y el deseo conduce a los personajes a repetir sus actos condicionando la realidad de los demás de forma que "Nuestras vidas están conectadas, un destino está ligado al siguiente. Cada uno de nuestros actos es meramente una respuesta a un acto anterior: Causa y efecto. No es otra cosa que una danza sin fin. Todo está conectado a todo lo demás” (Tannhaus, T1: E8).

La reiteración de los actos son consecuencia del deseo, un deseo no elegido y que pone el control fuera de la voluntad del individuo. El eterno retorno es la expresión de la persistencia del deseo. Asimismo, esa pulsión compulsiva de los personajes ha repetir sus actos se plasma visualmente en los símbolos (el número 33, el signo del infinito...) o de ambientación (bunker, bosque, iglesia, cueva, pueblo) reforzando narrativamente la impresión de siniestro.

No obstante, la narración encuentra limites dentro del discurso psicoanalítico como herramienta para producir lo siniestro. Es entonces cuando entra en funcionamiento la quiebra entre significantes y significados como realización alternativa de lo siniestro. Ya sea por la falta de nombres para etiquetar una realidad (ruptura de la linealidad en la estructura de parentesco) o por la desconfianza sobre el auténtico significado de las acciones (intención de los personajes). 


\subsection{La relatividad de lo absoluto}

Los viajes en el tiempo rompen con el orden sintagmático que sirve para expresar las posiciones de parentesco en el modelo psicoanalítico. Así, por ejemplo, cuándo un hijo es biológicamente su propio padre, ¿Cómo actúa el complejo de Edipo o el de castración? ¿Y cuando una hija es su propia madre, qué sucede con el complejo de Electra? Hay una parte de lo siniestro en la serie que surge de la angustia generada por la ruptura de los patrones que el psicoanálisis considera normalizados. En esa situación, donde los complejos no responden a un patrón lo siniestro emerge de un exceso y desbordamiento de la realidad. Algo que en otras creaciones artísticas se expresan como animales mitológicos (grifos, faunos...), o en Lovecraft como figuras indescriptibles y fuera de toda forma reconocible o conocida (significados sin significante) o como vacíos abismales (significantes sin significado).

La fractura de la linealidad temporal da forma a realidades sin nombre, donde se rompen los límites de la comprensión. La dicotomía hija/madre colapsa en una hija-madre, donde el personaje se engendró a si mismo. ¿Cómo denominar esa realidad ficticia? Es un recurso que se repite en la serie, con un hijo que es padre de sí mismo. Abundando en dicho juego entre significados y significantes, existe un personaje sin nombre, al ser hijo de una relación cruzada entre los dos mundos, que siempre se muestra con tres edades, ilustrando un personaje sin edad definida, habitando fuera del tiempo. Son múltiples los ejemplos presentes en la serie sobre la ruptura de la relación entre significantes y significados como consecuencia de la interacción entre dos mundos.

Una vez que se cancela el tiempo como parámetro que ordena las relaciones sintagmáticas, el sentido de la narración se dispersa alcanzando tal complejidad, que existen guías en internet donde se describen las relaciones de parentesco en los dos mundos.

\subsection{Personajes siniestros}

La borrosidad entre los significantes y los significados se extiende a la caracterización de los personajes y sus intenciones. Los personajes siniestros son un rasgo característico de esta serie. Para comprender el papel que desarrolla la figura del personaje siniestro en la trama argumental es importante recordar su grado de consciencia. Los personajes se dividen entre los que son conscientes de la existencia de un problema, plasmado en el eterno retorno, un ciclo continuo de destrucción y creación, y aquellos otros que experimentan una angustia inconsciente de estar atrapados en sus vidas, sin poder ofrecer una explicación a dicha sensación. La dualidad como recurso de lo siniestro adopta formas diversas según la estrategia narrativa, y en ocasiones es suficiente para comprender la lógica de la trama que produce lo siniestro, como es el caso del análisis de Rodríguez Serrano y García Catalán (2016) para la serie True Detective (HBO, 2014). En la serie Dark dicha dualidad generadora de lo siniestro se intensifica al intervenir el pliegue sobre la realidad que produce el recurso al psicoanálisis.

El diagrama 3 muestra la estructura de la narrativa que da lugar a lo siniestro según el papel desarrollado por los personajes y su grado de conocimiento. En un plano se desenvuelve la acción de los personajes que son conscientes de lo que sucede y mantienen un conflicto entre ellos. En la trama, son personajes que actúan de forma incomprensible pero que 
tienen un plan oculto que interviene en la vida cotidiana de los demás. Así, se intuye que el sacerdote que asesina niños en una máquina actúa de acuerdo con un fin desconocido y siniestro. Esos personajes que habitan en el envés de la trama habitan fuera del tiempo y en guerra con él: "Le hemos declarado la guerra al tiempo y le hemos declarado la guerra a Dios. Estamos creado un mundo nuevo, sin tiempo, sin Dios" (Adam, T2: E5).

La noción de plan oculto se visualiza entorno a la secta "Sic Mundus". En ella lo siniestro se arropa de una imaginería simbólica compleja, llena de significados, como la triqueta, el símbolo del infinito, la tabla esmeralda o los tatuajes, plasmando un discurso articulado simbólicamente con lo esotérico, la magia y lo sobrenatural. Tal y como comenta Santamaría Blanco (2013) respecto al movimiento simbolista:

La obra de arte equivale a una emoción provocada por la experiencia, por lo que tratan de exteriorizar una idea, de analizar el yo. (.../...) En sus obras establecen correspondencias entre objetos y sensaciones para lo que utilizan los símbolos, decantándose por lo sobrenatural, lo que no se ve, lo que las liga a la estética de lo siniestro (Santamaría Blanco, 2013: 57).

Es uno de los rasgos específicos en la serie: el continuo establecimiento de correspondencias entre objetos, entornos y sensaciones. Hasta tal punto, que la presentación de teorías racionales que explicarían su mundo se envuelve en una teatralidad que apela más a la emoción que a la razón.

Diagrama 3. El paradigma de lo siniestro en los personajes de Dark

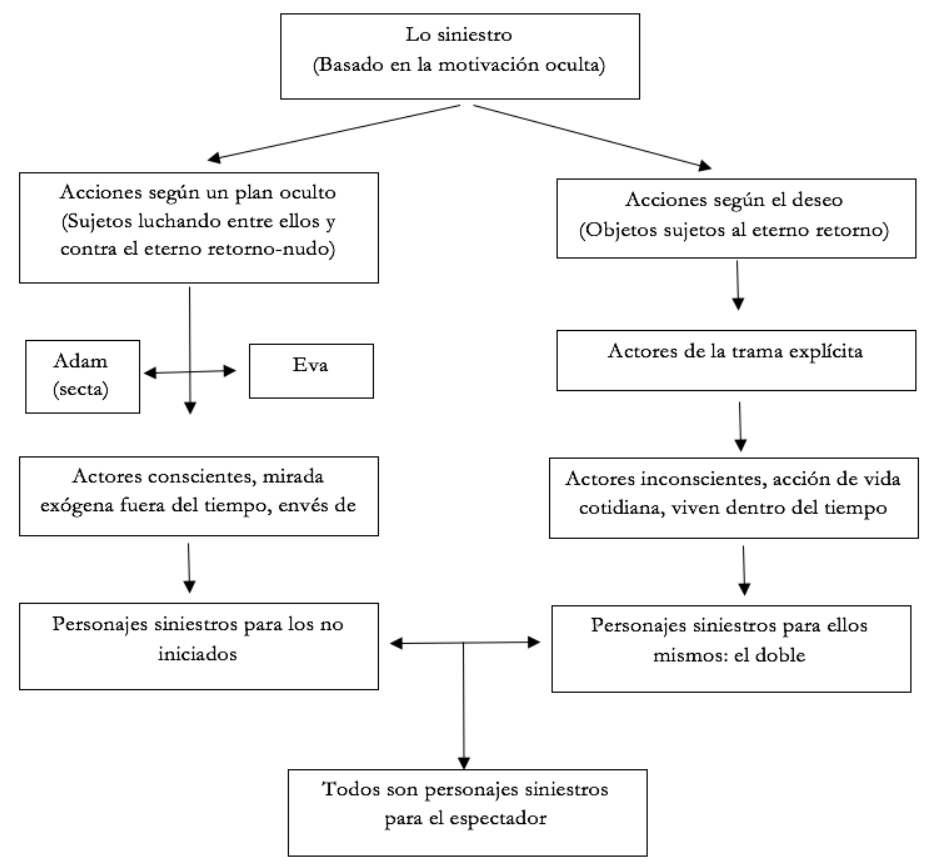

Fuente: elaboración propia 
El segundo grupo de personajes habitan en el mundo donde ocurren las situaciones y acontecimientos narrados (Prince, 2003); sus vidas cotidianas son el campo de batalla del primer grupo. No son conscientes de lo que sucede, y se sienten atrapados y en un continuo dejà vu. Un dejà vu que nombran como un "error en la matriz", en la misma dicotomía entre realidad y sueño de la película Matrix. El deseo de escapar de algo que es vago e impreciso se enuncia varias veces por diferentes personajes. La ilusión de abandonar la ciudad de Winden o que Winden no existiera. Estos personajes, cuando viven directamente lo extraño (viajes en el tiempo) se ven abrumados incapaces de asimilar la experiencia. El primer personaje que el espectador ve viajar en el tiempo escribe antes de suicidarse:

La verdad es extraña. Aunque intentemos suprimirla, siempre encuentra la forma de salir a la luz. Hacemos de nuestra mentira nuestra propia verdad para sobrevivir e intentamos olvidar hasta que ya no podemos más. No conocemos ni la mitad de los misterios de este mundo. Deambulamos en la oscuridad (Michael Kahnwald, T2: E6).

Son personajes perdidos y abrumados en un mundo que se les ha revelado como desconocido (en el tiempo y entre mundos alternativos) y conocido a la vez (es donde viven). Una extrañeza que permea lo cotidiano: "Estamos todos muy ciegos. Nos aferramos a la esperanza de que no nos suceda nada a nosotros. Creemos que conocemos a quienes nos rodean. ¿Pero es así? En realidad, no sabemos nada ni siquiera de nuestros vecinos" (K. Nielsen, T1: E6). En definitiva, la serie Dark ofrece un mundo particularmente siniestro al simultanear el ser conocido (significantes cotidianos) y a la vez extraño (en sus nuevos significados).

La amalgama temporal hace del tiempo (su ausencia) un actor más del drama. En el estudio de la contribución del tiempo a la generación de suspense Prósper Ribes (2019) señala la diferencia entre el tiempo diegético (cronología interna del mundo narrado) y el tiempo del discurso (percepción extradiegética del tiempo por parte del espectador).

Entre el tiempo de la historia y el tiempo del discurso se pueden plantear diferentes relaciones (Genette, 1989b), que establecerán la arquitectura temporal del discurso: duración, orden y frecuencia. Las posibilidades de manipulación temporal del tiempo del discurso son enormes, lo que permite configurar el sentido final del relato y la percepción del espectador. Como consecuencia, el espectador generará una respuesta emotiva ante las situaciones diegéticas que le son planteadas (Prósper Ribes, 2019: 305).

En el caso de la serie Dark, el tiempo no solo es un elemento constructivo en el desarrollo del conflicto sino la causa directa de él. El tiempo diegético se fragmenta, reordena y repite de forma que no existe expectativa de resolución por parte del espectador. En la narración las hipótesis que puedan dar respuestas son racionalizaciones que alejan de la realidad. Precisamente la angustia que alimenta lo siniestro surge del suspense que generan las tramas sin sentido aparente al fallar el orden causal que facilita el hilo del tiempo. Prósper Ribes (2019: 300), citando a Hitchcock, recuerda como el suspense y el miedo son emociones que pueden llegar a confundirse. En Dark el suspense se integra en la trama al servicio de lo 
siniestro, al igual que lo hacen otros dos elementos: curiosidad y sorpresa.

Esto es posible en la medida que los tres procedimientos (suspense, curiosidad y sorpresa) han sido definidos sobre la base del orden temporal. Prósper Ribes (2019:300), citando a Hoeken y van Vliet (2000: 277), afirma que el suspense se logra posponiendo el resultado o conclusión de la historia, la curiosidad se despierta mostrando el resultado primero y después lo que llevó a él y, finalmente, la sorpresa se produce mediante sucesos inesperados en el trascurso de la trama. Los tres recursos están presentes en la estructura narrativa de la serie gracias a la plasticidad narrativa y argumental que permite la manipulación del tiempo.

\section{Conclusiones}

Es frecuente que la interpretación de una creación artística de lugar a un debate sobre las intenciones de sus autores. En el caso que nos ocupa, la serie Dark, las citas textuales que aparecen como paratextos o diálogos de los personajes ofrecen suficientes indicios sobre la lógica de su diseño. Es una narración audiovisual que se inspira en el modelo psicoanalítico tanto en su estructura argumental como en los elementos figurativos, diálogos y banda sonora para lograr generar una impresión de siniestro. En ese sentido, ha entrado en la categoría de serie de culto, ofreciéndose como modelo de referencia narrativa tanto por su complejidad argumental como por la profundidad filosófica de sus diálogos.

El análisis permite observar en qué modo la serie Dark utiliza los procedimientos mostrados por Freud en su análisis de lo siniestro. Estos recursos son aplicados tanto en su organización argumental como narrativa mediante la caracterización de los personajes, muertes y mutilaciones, reiteraciones o los dobles; de hecho, explícitamente, como claves de arco argumental tras las acciones de los personajes se encuentran el deseo (su represión) así como el thanatos es circularmente el origen y el final.

El tema de la muerte se encuentra en la génesis de todo: la creación y la destrucción de los dos mundos. Tannhaus intenta evitar la muerte ya sucedida de su familia y destruye su mundo (creando dos): "Los muertos nunca están muertos. Quizá no estén aquí, ahora. Pero todo lo que ha vivido vive por siempre en la eternidad del tiempo" (Padre de Gustav Tannhaus, T3: E3). La racionalidad tras el deseo de suprimir la muerte desencadena una pesadilla, ejemplificada en la idea del eterno retorno. El trasfondo moral de Nietzsche, de vivir una vida que merezca la pena volver a vivir, se plasma en unas existencias condenadas a vivir eternamente los mismos errores. El eterno retorno en la serie es la fuente de la angustia que Freud ubicaba en el origen de lo siniestro. Una angustia expresada en dos formas, la de aquellos que la experimentan conscientes de su causa y los que no.

La única forma de escapar a la angustia que produce el eterno retorno es terminar con él. El personaje Claudia, que vive la muerte de su hija en los dos mundos, es quien de forma racional investiga empíricamente en la materia oscura hasta que finalmente descubre la respuesta: un mundo original del que surge accidentalmente sus mundos y sus vidas. Ellos habitan unos mundos oníricos y siniestros que son el resultado del deseo cumplido del relojero: "Hay una forma de destruir El Nudo: Evitar que en El Mundo de Origen se 
inventen los viajes en el tiempo y el espacio" (Claudia Tiedemann, T3: E8). El impulso que mueve a Claudia (al final) al igual que al relojero (al principio) es el deseo de evitar la angustia de la muerte. La solución sigue un planteamiento clínico psicoanalítico, donde solamente desde el principio de realidad es posible enfrentar la angustia y sus consecuencias. El resto de los personajes, operando en lo onírico como si fuese real eran incapaces de encontrar la salida del ciclo angustioso.

No obstante, sobre el planteamiento psicoanalítico básico de la serie se inscribe una fuente complementaria de lo siniestro. La angustia del eterno retorno se combina con los viajes en el tiempo. Este hecho, que permite dar una complejidad especial a las tramas y la imaginería psicoanalítica de lo siniestro, ofrece la oportunidad de emplear un nuevo recurso: lo aberrante. Esto es así, en la medida que la ruptura de la linealidad temporal permite una narración sintagmáticamente rota en lo que se refiere a la genealogía de los personajes. Con ello se vuelve borroso el significado que procede de la secuencia de los hechos y la historia de los personajes.

Lo siniestro surge de la pérdida del significado causada por la ruptura de las relaciones sintagmáticas. Al destruir el orden (posición de los significantes) la acción por sí misma, a falta de una explicación, se trasforma en un relato ininteligible en el que solo se conserva parte del sentido mediante las relaciones paradigmáticas (sustitución). Hijas que son sus madres, hijos que son sus padres, el colapso de las estructuras de parentesco desafía los complejos psicoanalíticos a la vez que da realidad a lo que es tan incomprensible que no tiene nombre. En ese sentido, lo siniestro que surge de la ruptura de la barra significante se une a lo siniestro de la imaginería psicoanalítica.

En la práctica la serie es un cruce de caminos en las dos categorías que propusiera Xenakis (1963) para el análisis de las composiciones musicales. Xenakis distinguía entre "estructuras en-el-tiempo" (fenómenos sujetos a la linealidad temporal, como una composición musical), y las "estructuras fuera-del-tiempo", constituido por el material no ordenado a partir del cual se crea la obra artística. La serie Dark, en ese sentido, está diseñada narrativamente como una "estructura fuera-del-tiempo" que ofrece al espectador una visión aparentemente caótica de la ejecución de un plan desconocido. En definitiva, muestra la realización narrativa de lo siniestro a partir del colapso del sintagma sobre el paradigma en el contexto de un discurso de fundamento psicoanalítico. En ello reside la originalidad que la ha convertido en serie de culto.

\section{Bibliografía}

Alaminos, A. (1999). Análisis de discurso. Alicante: Club universitario.

Alaminos-Fernández, A. F. (2020). La caracterización musical transmedia de las identidades juveniles: el caso de la serie Stranger Things. Fonseca, Journal of Communication, (21), 19: 87105. https://doi.org/10.14201/fjc20202187105

- (2019): La realidad aumentada. Música y comunicación en la sociedad de consumo. (Tesis inédita de doctorado). Universidad de Alicante, Alicante. http://hdl.handle.net/10045/103127 


\section{MHCJ Vol. 12 (1) | Año 2021 - Artículo nº 6 (173) - Páginas 119 a 140 - mhjournal.org}

- (2014): La música como lenguaje de las emociones. Un análisis empírico de su capacidad performativa. OBETS. Revista de Ciencias Sociales. 9 (1): 15-42. doi:10.14198/ OBETS2014.9.1.01

Barthes, R. (2003). El sistema de la moda y otros escritos. Barcelona: Paidós ibérica.

Carrasco Campos, A. (2010). Teleseries: géneros y formatos. Ensayo de definiciones. Miguel Hernándę Communication Journal, (1): 174-200. https://doi.org/10.21134/mhcj.v1i1.22

Casetti, F. (2005). Teorias del cine 1945-1990. Madrid: Cátedra.

Conde, A. (2006). Lo Siniestro enroscado a la Palabra. Lenguaje y extrañamiento a partir de la lectura de Lo siniestro de Freud. Espéculo. Revista de estudios literarios, 33.

Eco, U., e Irazazábal, M. P. (2007). Historia de la fealdad (Vol. 200). Barcelona: Lumen.

Freud S. (1919). Lo siniestro, en Obras completas, Edición digital Librodot.com. Disponible en https://www.ucm.es/data/cont/docs/119-2014-02-23-Freud.LoSiniestro.pdf

- (2000): Tres ensayos de teoría sexual en Obras completas Sigmund Freud. Volumen 7 (190105). Buenos Aires: Amorrortu editores.

Genette, G. (1989a). Palimpsestos: la literatura en segundo grado. Barcelona: Taurus.

—- (1989b). Figuras III. Barcelona: Lumen.

González Requena, J. (1997). Emergencia de lo siniestro. Trama y fondo, (2) 51-75.

- (1998): Lo Transparente y lo Siniestro, Trama y Fondo (4) 10-28.

Heidegger, M. (2012). El ser y el tiempo. Madrid: Trotta.

Hoeken, H. y van Vliet, M. (2000). Suspense, curiosity, and surprise: How discourse structure influences the affective and cognitive processing of a story. Poetics, $\mathrm{n}^{\circ} 27: 277-286$.

Kristeva, J. (1989). Poderes de la perversión. Madrid: Siglo Veintiuno Editores.

Lacan, J. (2006). El Seminario. Libro 10: La angustia. Buenos Aires: Editorial Paidós.

Lévi-Strauss C. (1968). Antropología estructural. Buenos Aires: Eudeba.

Morin, E. (2001). El cine o el hombre imaginario. Barcelona: Paidós.

Nietzsche, F. (2005). Así habló Zaratustra. Madrid: Valdemar.

Penalva, C. et al. (2015). La investigación cualitativa: técnicas de investigación y análisis con Atlas. Ti. Cuenca (Ec.): PYDLOS.

Prince, G. (2003). A Dictionary of Narratology. Lincoln \& London: University of Nebraska Press.

Prósper Ribes J. (2019). El suspense cinematográfico: montaje y organización temporal. 
MHCJ Vol. 12 (1) | Año 2021 - Artículo n 6 (173) - Páginas 119 a 140 - mhjournal.org

Miguel Hernández Communication Journal. Vol. 10 (2): 303-321. DOI: http://dx.doi. org $/ 10.21134 /$ mhcj.v10i0.309

Quirós Fernández, A. (2017). La estética de lo siniestro en el videoclip: integración de lo siniestro en el discurso audiovisual. Bajo palabra. Revista de filosofía, 2(14), 125-142.

Rank, O. (2004). El doble. JCE: Buenos Aires.

Rodríguez Serrano, A. y García Catalán, S. (2016). El hogar y el héroe: espacios y subjetividades en True Detective (HBO, 2014). Miguel Hernández. Communication Journal, (7): 5-30. https://doi.org/10.21134/mhcj.v0i7.106

Santamaría Blasco, L. (2013). ¿Qué me pasa doctor Freud?: una aproximación a lo siniestro en el arte y la cybercultura, y un epilogo gótico contemporáneo. Herejía y belleza: Revista de estudios culturales sobre el movimiento gótico, (1): 51-72.

Saussure F. (1973). Curso de linguïstica general. Buenos Aires: Editorial Losada.

Trías, E. (2006). Lo bello y lo siniestro. Buenos Aires: Editorial Ariel.

Xenakis I. (1963). Musiques formelles. París: La Revue Musicale. 
MHCJ Vol. 12 (1) | Año 2021 - Artículo n 6 (173) - Páginas 119 a 140 - mhjournal.org

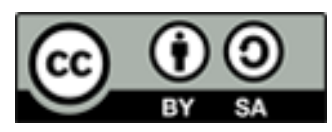

\author{
Licencia Creative Commons \\ Miguel Hernández Communication Journal \\ mhjournal.org
}

\title{
Cómo citar este texto:
}

Antonio Alaminos Fernández (2021): El diseño de lo siniestro en la serie televisiva Dark en Miguel Hernández Communication Journal, Vol. 12 (1), pp. 119 a 140. Universidad Miguel Hernández, UMH (Elche-Alicante). DOI: https://doi.org/10.21134/mhcj.v12i.934 